\title{
Saphenous vein harvest with the Mayo extraluminal dissector: Is endothelial function preserved?
}

\author{
Pradeep Narayan, FRCS, Mark Yeatman, FRCS, Massimo Caputo, MD, Radek Capoun, MRCS, \\ Franco Ciulli, FRCS, Jamie Y. Jeremy, PhD, and Gianni D. Angelini, FRCS, Bristol, United Kingdom
}

Despite a significantly lower incidence of wound infection rates ${ }^{1}$ and compelling evidence that there is no difference in the degree of preservation of histologic architecture, vascular tone, or vasomotor reactivity of veins harvested with the Mayo dissector (Johnson and Johnson, Langhorne, PA) and a similar graft patency compared with the open method, ${ }^{2}$ use of the Mayo dissector still remains limited, probably because of a lack of evidence regarding the functional quality of the vein. In modern practice, although endoscopic vein harvest is gaining popularity, the Mayo dissector (Figure 1) still remains a satisfactory and inexpensive, albeit underused, alternative for vein harvesting, and hence we sought to examine the functional quality of the veins harvested with the Mayo extraluminal dissector.

Nitric oxide (NO), a vasoactive molecule produced from the endothelium, is a marker of endothelial function. NO is associated with a diminished incidence of neointimal proliferation, producing these effects through stimulation of soluble guanylate cyclase and generation of cyclic guanosine monophosphate (cGMP). To compare the functional ability of harvested saphenous veins with the Mayo stripper and conventional open dissection, we measured cGMP production ex vivo after stimulation with specific activators of the NO-cGMP axis.

\section{CLINICAL SUMMARY}

After obtaining informed consent, a consecutive series of 32 patients (25 male patients; age range, 46-80 years; median, 67 years) undergoing coronary artery bypass grafting were prospectively randomized into one of 2 groups to have their saphenous veins harvested either by means of conventional open dissection or with a Mayo dissector. This was carried out by residents of similar surgical experience and expertise.

Harvesting of veins by means of the open technique was performed in the standard manner. In all cases, dissection was started at the distal end of the vein. A $10-\mathrm{cm}$ incision

From the Bristol Heart Institute, Bristol Royal Infirmary, Bristol, United Kingdom. Received for publication March 5, 2008; revisions received March 28, 2008; accepted for publication April 20, 2008; available ahead of print Sept 1, 2008.

Address for reprints: Gianni D. Angelini, FRCS, Bristol Heart Institute, Bristol

Royal Infirmary, Bristol BS2 8HW, United Kingdom (E-mail: G.D.Angelini@ bristol.ac.uk).

J Thorac Cardiovasc Surg 2009;138:508-10

$0022-5223 / \$ 36.00$

Copyright (c) 2009 by The American Association for Thoracic Surgery doi:10.1016/j.jtcvs.2008.04.024 was made at the ankle, and the vein was identified. The incision was then extended onto the skin with McIndoe scissors. Care was taken to ensure minimal handling of the vein, holding only the adventitia for mobilizing the vein. Branches were ligated with a medium clip (Horizon medium titanium clips; Weck, High Wycombe, United Kingdom) or with 4-0 coated, braided silk (USS/DG UMECO Inc, San Juan, Puerto Rico) sutures. The subcutaneous fat was closed in 1 or 2 layers with 2-0 polyglactin 910 vieryl (Ethicon, Inc, Somerville, NJ) sutures, and the skin was sutured with subcuticular coated, undyed 3-0 Vicryl sutures. On average, 15 to $18 \mathrm{~cm}$ of vein was harvested for each coronary artery to be bypassed.

Subcutaneous harvesting was performed with an extraluminal vein dissector (Mayo vein stripper; Johnson and Johnson, Langhorne, $\mathrm{Pa}$ ) and started at the proximal end in the groin. After the vein was suture ligated and divided from the saphenofemoral junction, it was dissected free from surrounding tissues, and its branches were clipped on the patient's side and cut. The vein was then brought out through a more distal incision with the help of the Mayo stripper. Through multiple incisions along the course of the long saphenous vein, the desired length of the vein was harvested. Care was taken to minimize traction on the vein, and the vein was periodically soaked with heparinized saline to prevent desiccation. Once the vein was harvested, the side branches were secured with medium titanium clips (Horizon medium titanium clips, Weck) or with 4-0 silk sutures.

A 2- to 3-cm-long segment of undistended vein was placed in Krebs-Ringer bicarbonate buffer pregassed with oxygen/carbon dioxide, transported to the laboratory, and then cut into rings and placed in Krebs-Ringer bicarbonate buffer containing $250 \mu \mathrm{mol}$ of isobutylmethyl xanthine to inhibit phosphodiesterase activity and breakdown of

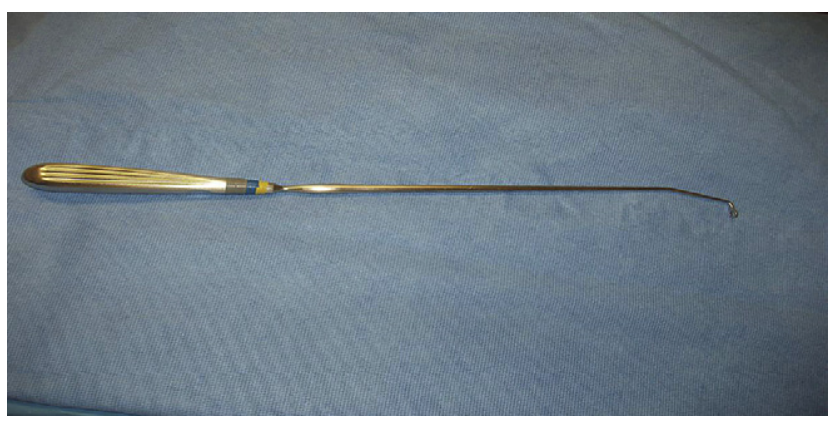

FIGURE 1. The Mayo extraluminal vein dissector. 
TABLE 1. Baseline characteristics

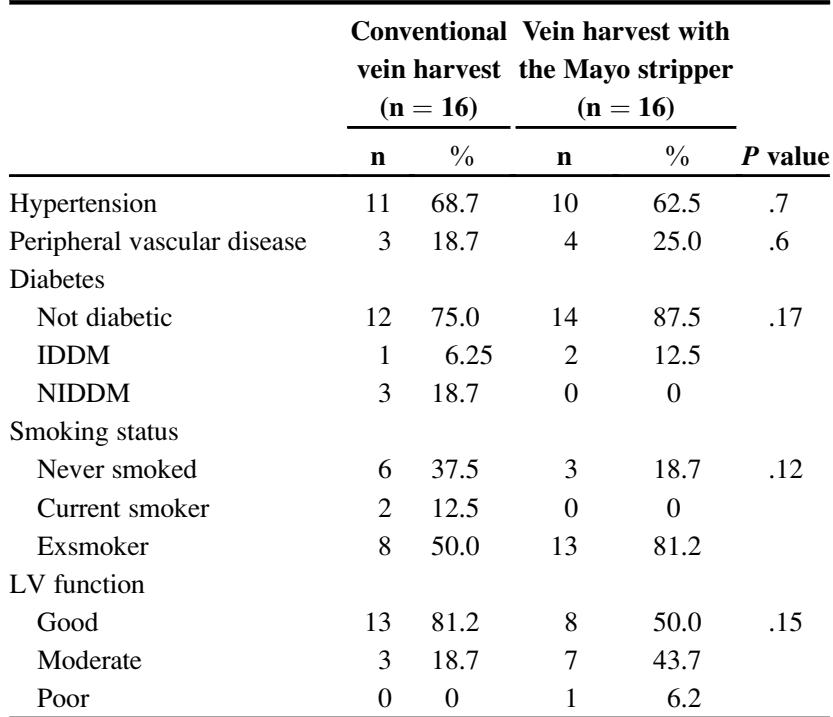

$I D D M$, Insulin-dependent diabetes mellitus; $N I D D M$, non-insulin-dependent diabetes mellitus; $L V$, left ventricular

cGMP. The basal cGMP levels were measured, and the following stimulators were added. First, sodium nitroprusside activates guanylcyclase directly, bypasses the release of NO from the endothelium, and is therefore an index of cGMP-synthesizing capacity. Second, A2387, a calcium ionophore, increases calcium levels in the endothelium, thereby activating NO synthase (NOS), and is therefore an index of endothelial NOS activity and an index of endothelial integrity. Finally, acetylcholine generates inositol triphosphate, which stimulates calcium mobilization, thereby activating endothelial NOS and NO formation. Because acetylcholine classically activates NOS in endothelial cells, it is therefore an index of endothelial integrity.

After incubation at $37^{\circ} \mathrm{C}$ for 30 minutes, reactions were stopped with perchloric acid and extracted, and cGMP levels were measured with specific cGMP radioimmunoassays.

Baseline characteristics were similar in the 2 groups (Table 1). The basal cGMP production was similar between conventional vein harvesting and use of the Mayo dissector ( $2.65 \pm 1.408$ vs $2.875 \pm 0.806 \mathrm{fmol} / \mathrm{mg}$ of tissue per minute; $P=.54 ; 95 \%$ confidence interval, -1.079 to 579$)$. Production of cGMP after stimulation with acetylcholine, sodium nitroprusside, and A23187 was also similar across the 2 groups (Table 2).

\section{DISCUSSION}

Thrombosis and neointimal hyperplasia in the early postoperative period and atherosclerosis in the late postoperative period are the primary causes of vein graft failure. ${ }^{3}$ Loss of endothelium eliminates the physical and electrostatic barrier separating platelets from subendothelial collagen, binding to which initiates platelet activation and resultant thrombotic occlusion. Endothelial loss is also associated with neointi-
TABLE 2. cGMP production after stimulation with NO-cGMP axis activators

\begin{tabular}{lccc}
\hline & & $\begin{array}{c}\text { Vein harvest } \\
\text { Conventional } \\
\text { vith the Mayo } \\
\text { Stripper* }\end{array}$ & $\begin{array}{c}\boldsymbol{P} \\
\text { value }\end{array}$ \\
\hline Acetylcholine $(1 \mu \mathrm{m})$ & $4.44 \pm 1.54$ & $4.63 \pm 0.95$ & .6 \\
Acetylcholine $(10 \mu \mathrm{m})$ & $9.93 \pm 4.07$ & $11.81 \pm 4.76$ & .2 \\
Sodium nitroprusside $(1 \mu \mathrm{m})$ & $21.25 \pm 6.63$ & $20.12 \pm 4.25$ & .5 \\
Sodium nitroprusside $(10 \mu \mathrm{m})$ & $79.81 \pm 20.15$ & $77.31 \pm 13.44$ & .6 \\
A23187 $(1 \mu \mathrm{m})$ & $5.43 \pm 1.99$ & $5.75 \pm 1.69$ & .6 \\
A23187 $(10 \mu \mathrm{m})$ & $11.37 \pm 4.78$ & $13.18 \pm 4.66$ & .2 \\
\hline
\end{tabular}

cGMP, Cyclic guanosine monophosphate; $N O$, nitric oxide. *Data are reported as means \pm standard deviation. Values are presented as femtomoles per milligram of tissue per minute.

mal hyperplasia and results in reduced production of $\mathrm{NO}^{4}$ NO has an important role in the prevention of vein graft failure..$^{5}$ Apart from being a potent vasodilator and possessing antiplatelet activity, NO limits neointimal hyperplasia by inhibiting smooth muscle cell proliferation and induces cell death by means of apoptosis.

Irrespective of the agonist used, this study demonstrates that there was no difference in cGMP production between the 2 groups. In turn, this indicates that the relative amount of endothelium and production of NO does not differ between the 2 groups. Moreover, although loss of endothelium and NO might be axiomatic in mediating vein graft failure, a host of factors, such as distension pressure, storage temperature and solutions, target vessel diameter, and surgical technique, all play an important role. ${ }^{5-8}$

With respect to leg wound infections, minimally invasive techniques, such as the Mayo extraluminal dissector and endoscopic vein-harvesting techniques, have been shown to reduce the incidence of theses complications significantly. ${ }^{2,9}$ Both techniques, however, differ in terms of surgical approach and are rather different in terms of cost.

Unlike the Mayo dissector technique, in which vein harvesting is initiated in the groin, endoscopic vein harvesting with the VasoView endoscopic system (Origin Medsystems, Menlo Park, Calif) is started with an incision at the medial aspect of the knee. Blunt dissection, carbon dioxide insufflation at a pressure of 12 to $15 \mathrm{~mm}$ through an insufflation port, and balloon inflation can all be used to aid the procedure. Bipolar scissors are used commonly to ligate the vein tributaries, an additional proximal incision at the ankle and a distal incision at the groin are made, and the desired length of vein is harvested. ${ }^{10}$

However, the more important difference is in terms of the financial burden. The endoscopic vein-harvesting technique uses a disposable system that can cost from $\$ 450$ to $\$ 550$ per patient, to which must be added the initial cost of setup of video monitors and cameras. ${ }^{10}$ On the other hand, the Mayo dissector is a reusable instrument of negligible cost.

In light of the findings of our own study and data from the available literature, we conclude that use of the Mayo 
extraluminal vein stripper preserves endothelium in a similar fashion as conventional vein harvest. This, coupled with the established superiority of the Mayo stripper in reducing postoperative leg wound infections, the short learning curve, and no additional financial implications, makes the use of this underused surgical aid from the past a very attractive option, even in the modern era.

\footnotetext{
References

1. Dimitri WR, West IE, Williams BT. A quick and atraumatic method of autologous vein harvesting using the subcutaneous extraluminal dissector. J Cardiovasc Surg (Torino). 1987;28:103-11.

2. O'Regan J, Borland JAA, Chester AH, Pennell DJ, Yacoub M, Pepper JR. Assessment of human long saphenous vein function with minimally invasive harvesting with the Mayo stripper. Eur J Cardiothorac Surg. 1997;12:428-35.

3. Bryan AJ, Angelini GD. The biology of saphenous vein graft occlusion: etiology and strategies for prevention. Curr Opin Cardiol. 1994;9:641-9.
}

4. Logerfo FW, Quist WC, Cantelmo NL, Haudenschild CC. Integrity of vein grafts as a function of initial intimal and medial preservation. Circulation. 1983;68:117-24.

5. Shuhaiber JH, Evans AN, Masssad MG, Geha AS. Mechanisms and future directions for prevention of vein graft failure in coronary bypass surgery. Eur J Cardiothorac Surg. 2002;22:387-96.

6. Zilla P, Von Oppell U, Deutsch M. The endothelium: a key to the future. J Card Surg. 1993;8:32-60.

7. Cataldo G, Braga M, Pirotta N, Lavezzari M, Rovelli F, Marubini E. Factors influencing 1 year patency of coronary artery saphenous vein grafts. Studio Indobufene nel Bypass Aortocoronarico (SINBA). Circulation. 1993;88:II93-8.

8. Paz MA, Lupon J, Bosch X, Pomar JL, Sanz G. Predictors of early saphenous vein aortocoronary bypass graft occlusion. The GESIC Study Group. Ann Thorac Surg. 1993;56:1101-6.

9. Isgro F, Weisse U, Voss B, Kiessling AH, Saggau W. Minimally invasive saphenous vein harvesting: is there an improvement of the results with the endoscopic approach? Eur J Cardiothorac Surg. 1999;16(suppl):S58-60.

10. Carpino PA, Khabbaz KR, Bojar RM, Rastegar H, Warner KG, Murphy RE, et al. Clinical benefits of endoscopic vein harvesting in patients with risk factors for saphenectomy wound infections undergoing coronary artery bypass grafting. J Thorac Cardiovasc Surg. 2000;119:69-76.

\title{
Minimally invasive transaortic thoracoscopic resection of an apical left ventricular myxoma
}

\author{
Paul Modi, FRCS, Ansar Hassan, MD, PhD, and W. Randolph Chitwood, Jr, MD, Greenville, NC
}

Minimally invasive cardiac valvular surgery is associated with decreased pain, reduced blood loss, faster recovery, superior cosmetic results, and greater patient satisfaction when compared with sternotomy approaches. Despite this, these techniques have rarely been used for intracardiac tumor resections, which have traditionally been performed through a median sternotomy. Tumors situated in the left ventricular apex represent a surgical challenge because it is a difficult area to access without a left ventriculotomy and its attendant complications. A recent report in the Journal describes the use of a thoracoscopic transaortic approach to resect a left ventricular fibroelastoma through a median sternotomy. ${ }^{1}$ To combine a thoracoscopic instrument with a median sternotomy seems paradoxical, and therefore we describe a truly minimally invasive approach to an apical left ventricular myxoma that we have used involving a thoracoscopic approach combined with a right anterior minithoracotomy.

\footnotetext{
From the East Carolina Heart Institute, East Carolina University, Greenville, NC. Received for publication March 21, 2008; accepted for publication April 13, 2008 Address for reprints: W. Randolph Chitwood, Jr, MD, East Carolina Heart Institute, East Carolina University, Pitt County Memorial Hospital, 600 Moye Blvd, Greenville, NC, 27834 (E-mail: chitwoodw@ecu.edu).

J Thorac Cardiovasc Surg 2009;138:510-12

0022-5223/\$36.00

Copyright (c) 2009 by The American Association for Thoracic Surgery doi:10.1016/j.jtcvs.2008.04.025
}

\section{CLINICAL SUMMARY}

A 65-year-old asymptomatic man, while undergoing echocardiographic work-up for a cardiac murmur, was discovered to have a $12-\mathrm{mm} \times 9-\mathrm{mm}$ tumor at the junction of the mid and apical lateral segments of the left ventricle (Figure 1, A). There was no significant valvular disease nor was there any history of thromboembolic events. There was no significant coronary disease. He was referred for surgical excision, which was accomplished with a minimally invasive technique.

A left-sided, double-lumen endotracheal tube and a 17F right internal jugular-superior vena cava Bio-medicus cannula (Medtronic, Inc, Minneapolis, Minn) were positioned. The right chest was elevated $20^{\circ}$, and a $5-\mathrm{cm}$ right anterior (second intercostal space) minithoracotomy was made just lateral to the right internal thoracic artery. A soft tissue retractor (Cardiovations; Edwards Lifesciences, Irvine, Calif) was deployed, and a pericardial well was created. A 5-mm videoscope port was positioned lateral to the incision, and a voiceactivated robotic arm was used for camera manipulation (AESOP 3000; Computer Motion, Inc, Galeta, Ca). The operative field was flooded with carbon dioxide $(4 \mathrm{~L} / \mathrm{min})$.

The femoral vessels were cannulated through a $2-\mathrm{cm}$ groin incision with the Seldinger guidewire-transesophageal echocardiographic visualization method (arterial: 17F-19F cannula, venous: 22F-25F long multistage cannula). After commencing vacuum-assisted cardiopulmonary bypass, 